\title{
ТЕХНИКА ВЫПОЛНЕНИЯ И МЕТОДИКА ОБУЧЕНИЮ САЛЬТО НАЗАД В ГРУППИРОВКЕ НА БРЕВНЕ
}

\author{
Парахин Виктор Александрович \\ Кандидат педагогических наук, доцент \\ РОССИЙСКИЙ ГОСУДАРСТВЕННЫЙ УНИВЕРСИТЕТ \\ ФИЗИЧЕСКОЙ КУЛЬТУРЫ, \\ СПОРТА, МОЛОДЁЖИ И ТУРИЗМА (ГЦОЛИФК) \\ Россия, г. Москва \\ Лялина Анастасия Александровна \\ Студентка 4 курса \\ РОССИЙСКИЙ ГОСУДАРСТВЕННЫЙ УНИВЕРСИТЕТ \\ ФИЗИЧЕСКОЙ КУЛЬТУРЫ, \\ СПОРТА, МОЛОДЁЖИ И ТУРИЗМА (ГЦОЛИФК) \\ Россия, г. Москва
}

Аннотация. В статье описывается биомеханический анализ техники выполнения гимнастического элемента сальто назад в группировке на бревне, который позволит осуществить поиск технических решений, позволяющих спортсменкам достичь возможно более высокой энергетики движения.

Abstract. The article describes a biomechanical analysis of the technique of performing a gymnastic element of a backflip in a grouping on a log, which will allow the search for technical solutions that allow athletes to achieve the highest possible energy of movement.

Ключевые слова: спортивная гимнастика, тренировочный процесс, женское многоборье, упражнения на бревне.

Keywords: gymnastics, training process, women's all-around, balance beam exercises.

Обучение гимнастическим упражнениям - это педагогический процесс, который требует планомерной и методично слаженной организации действий от преподавателя и ученика.

Этот процесс направлен на решение основных задач обучения:

а) формирования двигательных навыков и умений;

б) развитие комплекса физических качеств, воспитания морально-волевых качеств занимающихся [1,2].

Помимо основных задач решаются и многие другие. Так, например, в одном случае может изучаться комплекс хореографических упражнений, а в другом базовые акробатические элементы необходимые для освоения программ на других гимнастических снарядах. Таких ситуаций много. Но в любом случае главным требованием будет усвоение действий путём методики, в основе которой лежит использование дидактических принципов обучения, физиологических закономерностях становления двигательного навыка, фундаментальных положений теории физического воспитания[3,4]. Провести ученика по наиболее короткому пути и сформировать при этом необходимые навыки - главная задача тренера.

Цель исследования заключалась, в разработке комплекса основных и подводящих упражнений для освоения элемента сальто назад в группировке на бревне.

Объект исследования. Учебно-тренировочный процесс гимнасток этапа спортивного совершенствования.

Предмет исследования. Методика обучению элементу сальто назад в группировке на бревне.

Сальто назад, в группировке на бревне имеет группу трудности “С” и оценивается в 0,3 балла, по правилам соревнований женской спортивной гимнастики FIG 2022-2024 года.

Для структурного анализа нашего исследования мы использовали метод видеоанализа двигательных действий. На тело гимнастки наклеивались маркеры на голеностопный, коленный, тазобедренный, плечевой и локтевой суставы рисунок 1. Затем по движениям маркеров отслеживалась траектория движения каждого сустава. 


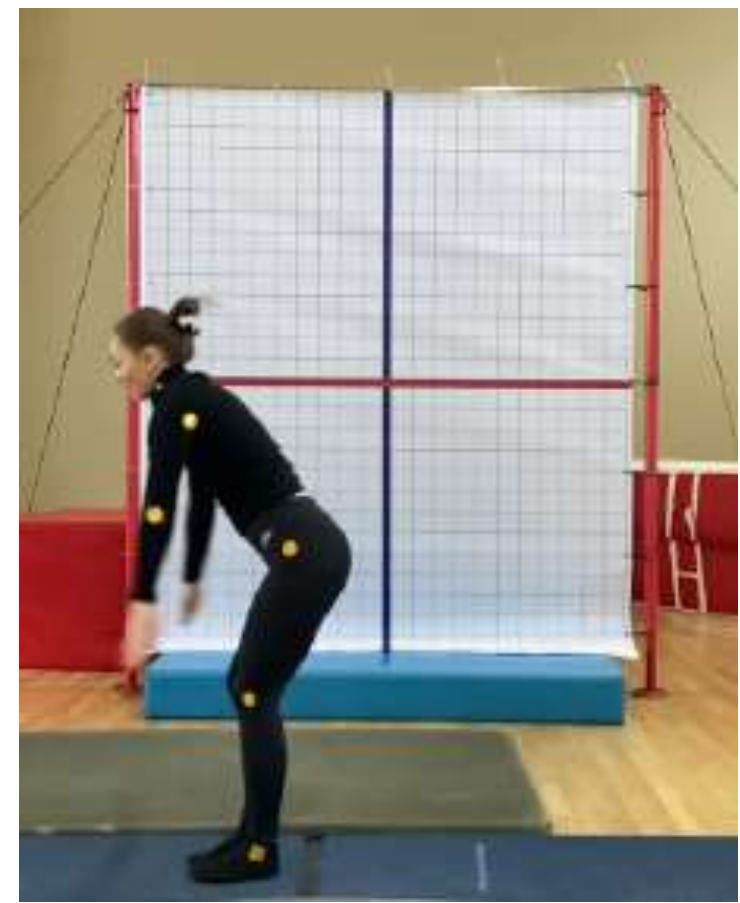

Рисунок 1. Маркеры на теле гимнастки

Нами было проанализировано выполнение сальто назад в группировке, двумя различными гимнастками. На рисунке 2 и 3 изображены подготовительные действия.
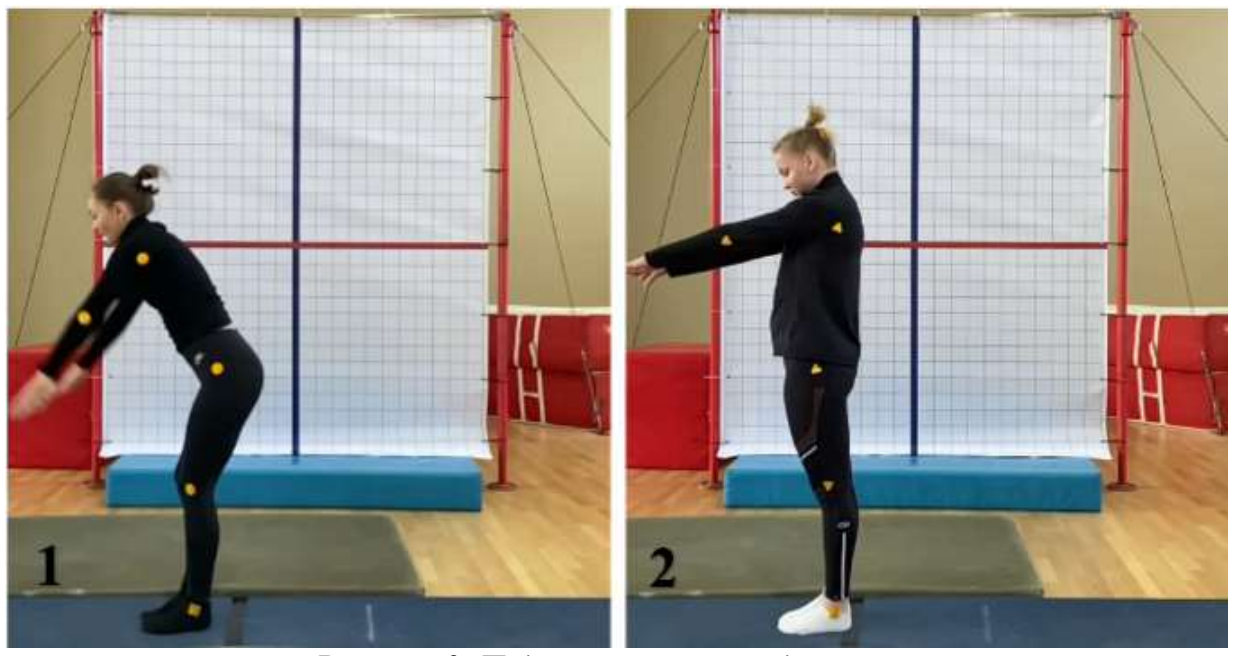

Рисунок 2. Подготовительные действия 

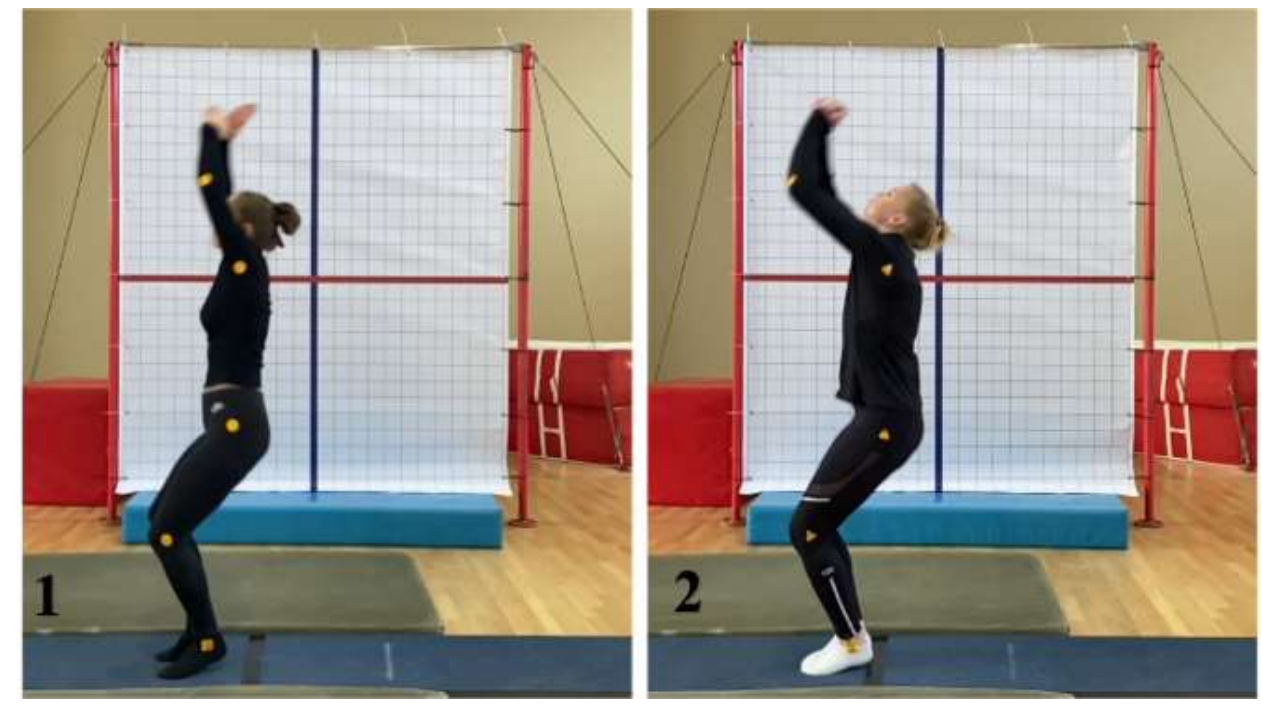

Рисунок 3. Подготовительные действия

Гимнастки делают небольшой сгиб в коленных суставах руки направленны вперед-вниз, затем резко выпрямляя ноги гимнастки делают взмах руками вперед-вверх. Затем гимнастки переходят в безопорное положение и выполняют основные действия рисунок 4 и 5.
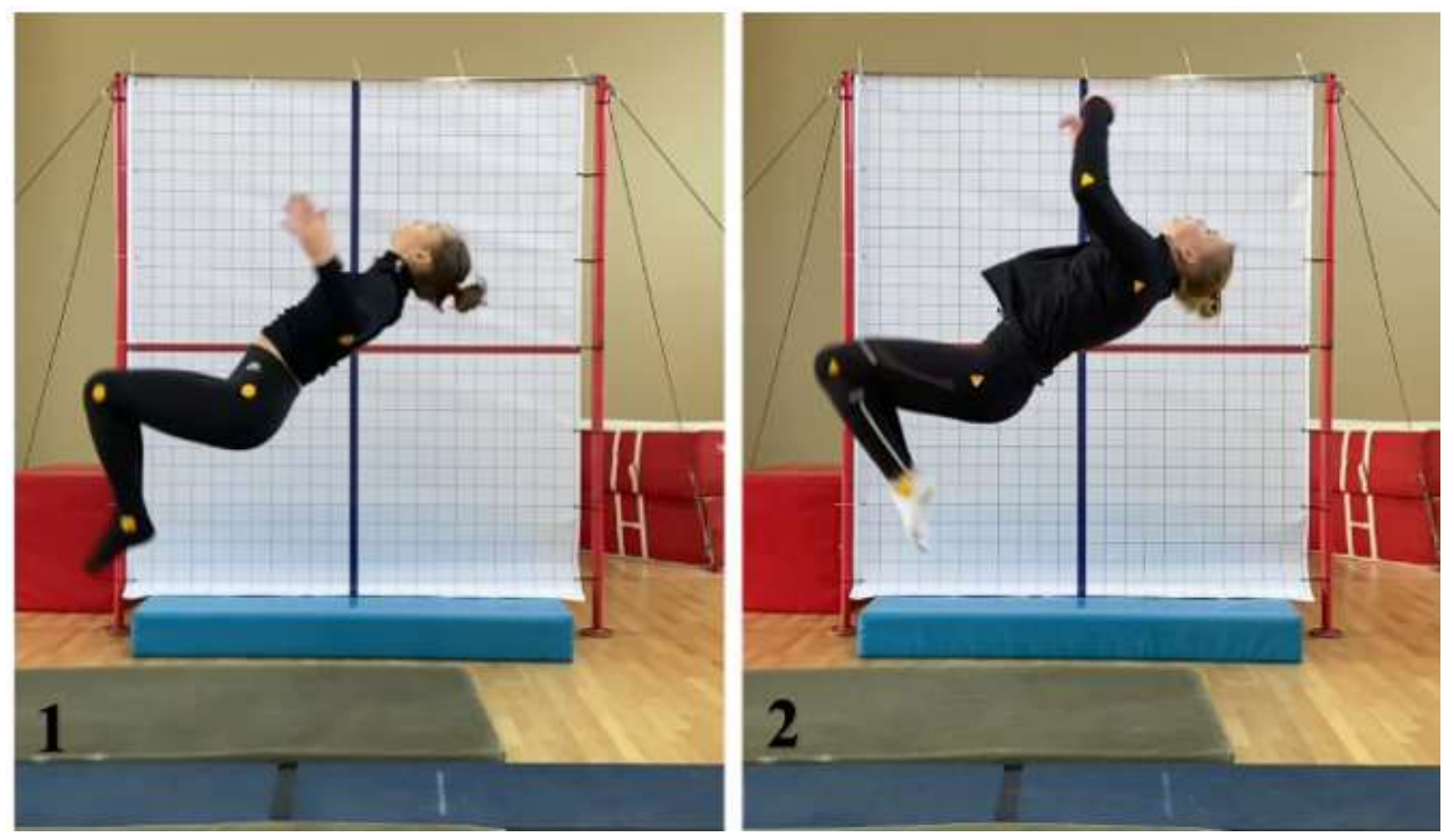

Рисунок 4. Основные действия 

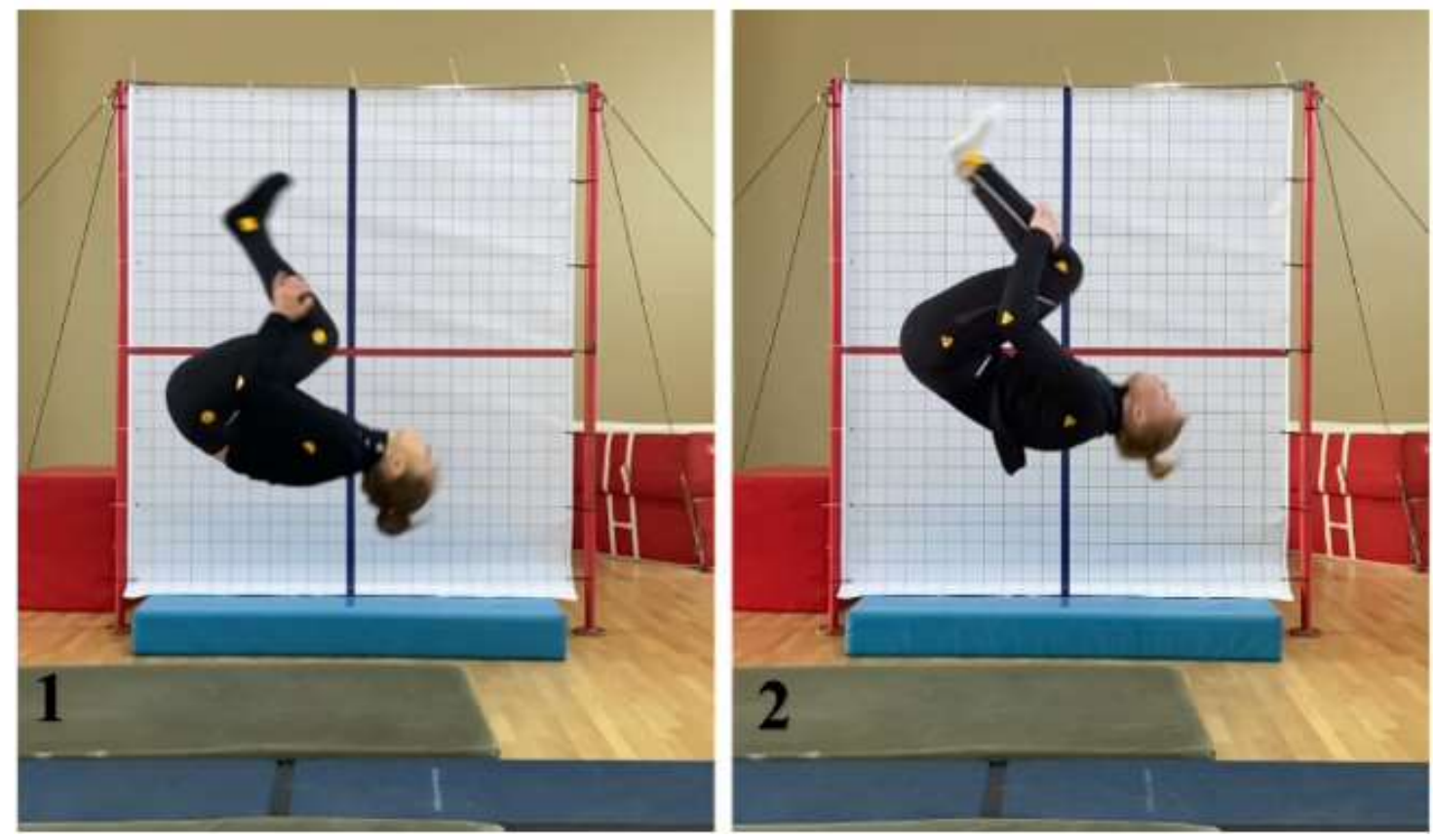

Рисунок 5. Основные действия
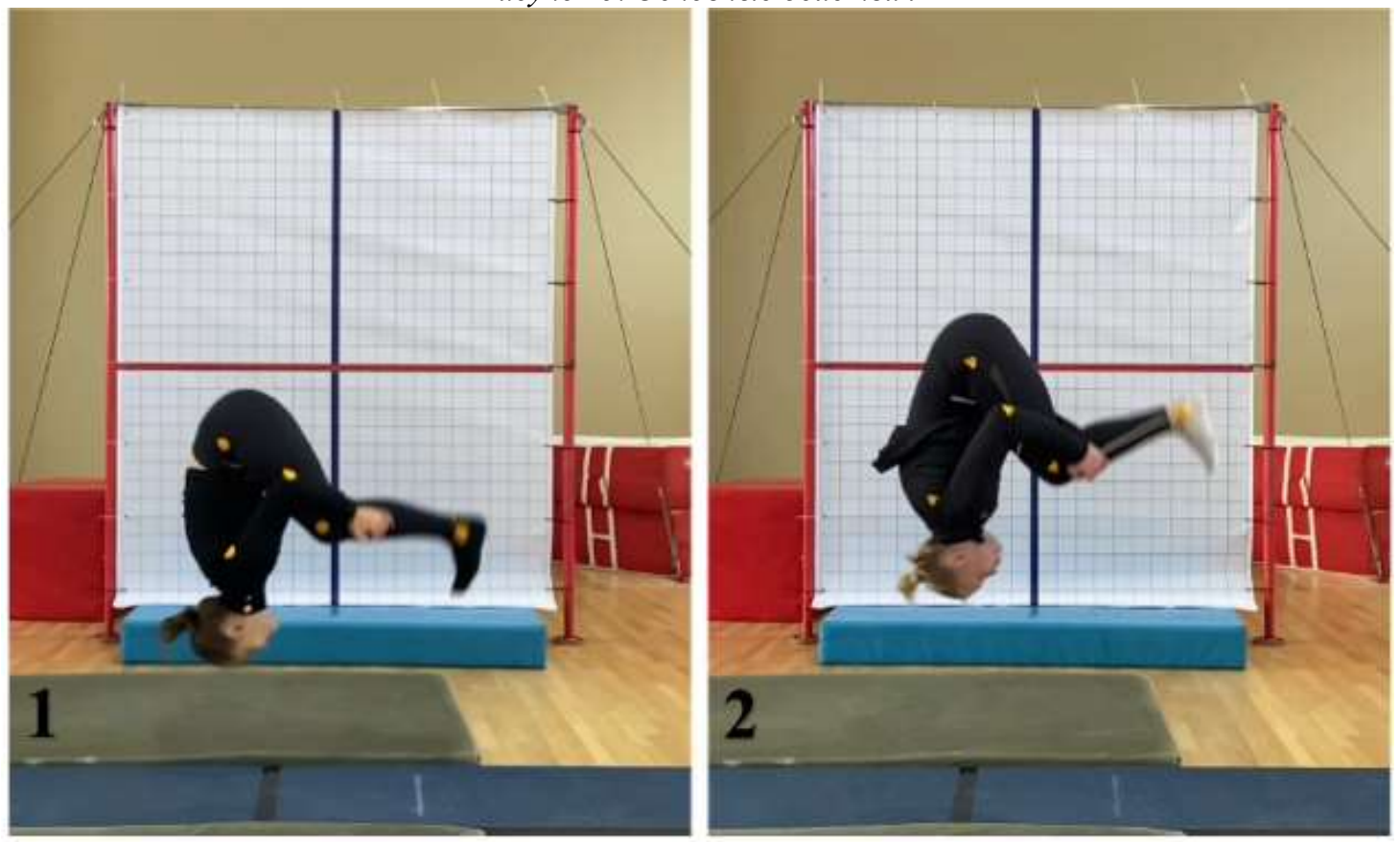

Рисунок 6. Основные действия

Основные действия или действия реализации это переход в безопорное положение рисунки 4,5,6 гимнастки отталкиваются вверх при этом делают небольшой прогиб в спине и резко сгибают ноги в коленных и тазобедренных суставах. Следующее действие гимнасток резкое сокращение мышц брюшного пресса и взятие группировки, при этом гимнастки выполняют вращательное движение по сальто назад. После выполнения основных действий гимнастки готовятся к приземлению и выполняют так называемые завершающие действия рисунок 7 и 8, гимнастки зрительно наблюдают опору и начинают разгибаться в тазобедренных суставах одновременно выпрямляя ноги при этом стопы становятся на опору, после того как гимнастки коснулись стопами опоры они выпрямляются в положение стоя руки вниз вперед. 

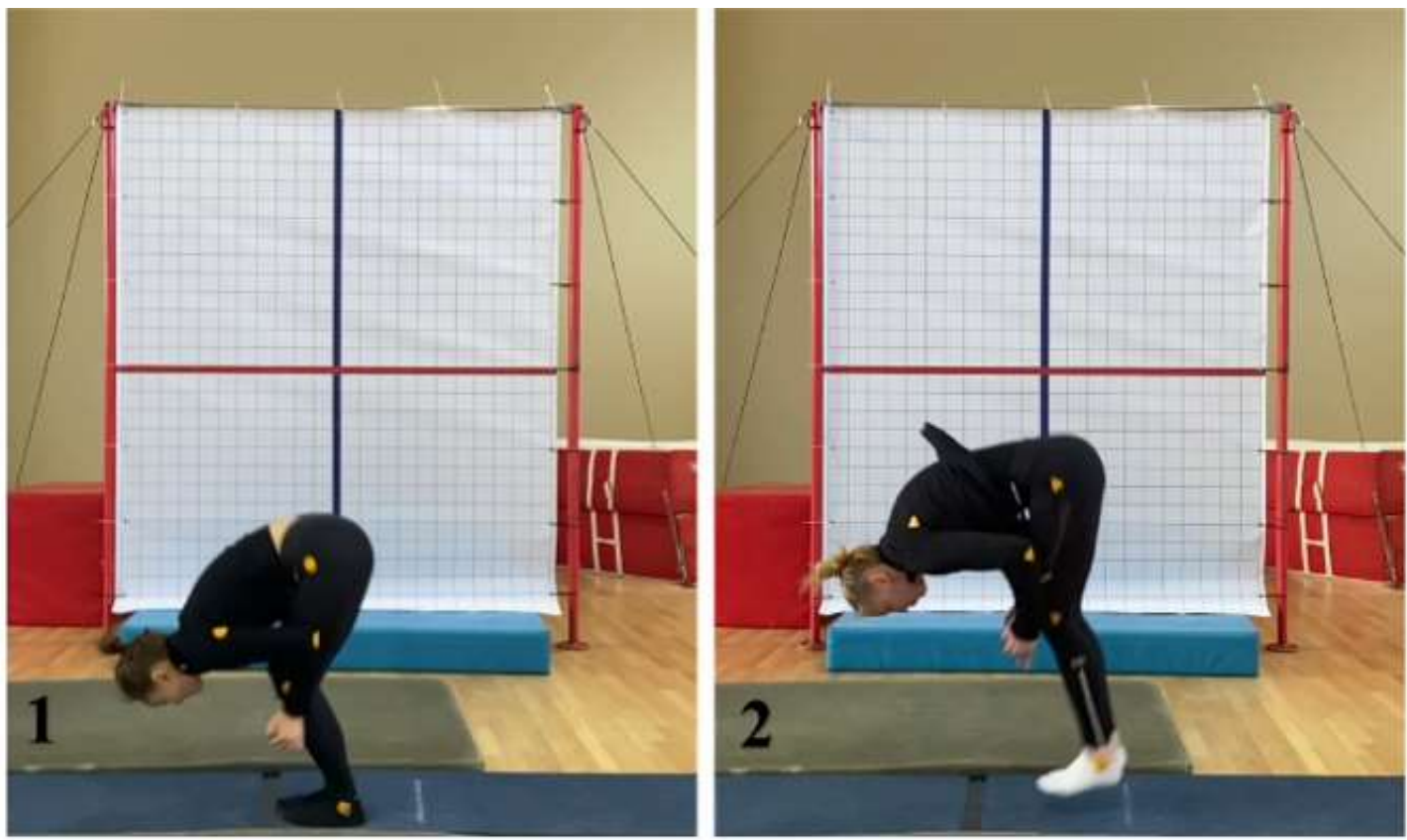

Рисунок 7. Завершающчие действия

С помощью видеоанализа можно не только изучать структуру двигательного действия, но и выявлять некоторые ошибки. Благодаря видеоанализу можно сделать заключение о том что для технически грамотного выполнения сальто назад в группировке высота ОЦМ тела гимнастки в высшей точки безопорных действий должна составлять от 110 см до 130 см.
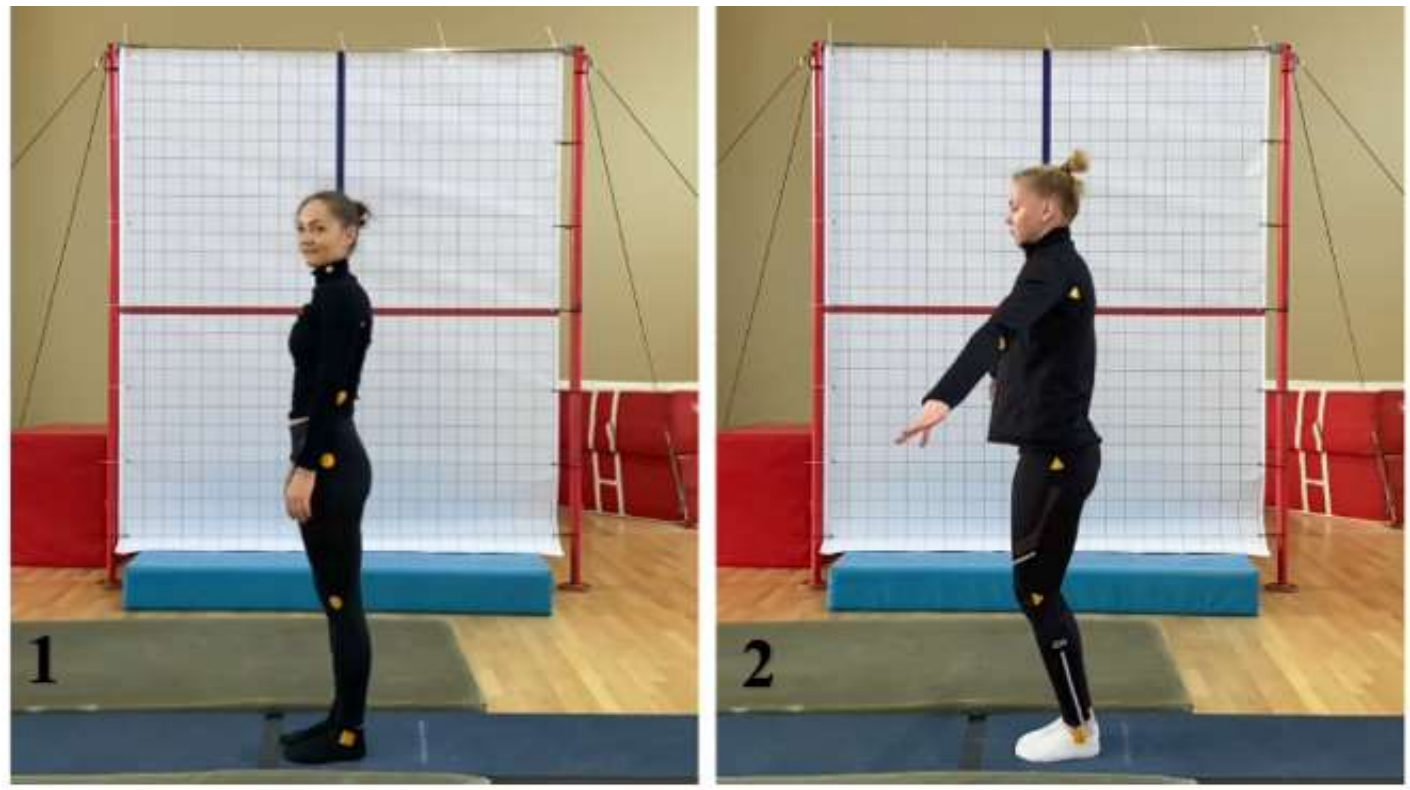

Рисунок 8. Завершающие действия

Следующая часть нашего исследования - это разработка специальных упражнений для освоения сальтовых вращений как на акробатике, так и для выполнения упражнений на бревне.

Для качественного освоения элемента сальто назад в группировке на бревне, нами был разработан ряд упражнений, мы условно их разделили на две группы: основные и подводящие.

К подводящим упражнениям относятся:

1. Сальто назад в группировке на гимнастическом ковре на жесткую опору

2. Сальто назад в группировке на напольном бревне со страховкой тренера

3. Сальто назад в группировке на напольном бревне на гимнастический мат (толщина мата 10 см)

4. Сальто назад в группировке на напольном бревне на гимнастический мат (толщина мата 5 см) 
5. Сальто назад в группировке на низком бревне (высота бревна 50 см от пола) со страховкой тренера

6. Сальто назад в группировке на низком бревне (высота бревна 50 см от пола) на гимнастический мат (толщина мата $10 \mathrm{~cm}$ )

7. Сальто назад в группировке на низком бревне (высота бревна 50 см от пола) на гимнастический мат (толщина мата $5 \mathrm{~cm}$ )

8. Сальто назад в группировке на стандартном бревне на гимнастический мат (толщина мата 10 см)

9. Сальто назад в группировке на стандартном бревне на гимнастический мат (толщина мата 5 см)

К основным упражнениям относятся:

1. Сальто назад в группировке на гимнастическом ковре

2. Сальто назад в группировке на напольном бревне

3. Сальто назад в группировке на низком бревне (высота бревна 50 см )

4. Сальто назад в группировке на стандартном бревне

Мы рекомендуем выполнять элементы в строгой последовательности, от простого к сложному, от освоенного к неосвоенному, только когда освоен более легкий вариант, можно переходить к освоению более сложного варианта исполнения элемента либо в усложненных условиях.

Заключение.

На основе результатов нашего исследования можно сделать выводы о том, что особенности методики обучения сальто назад на бревне заключается в систематическом и последовательном обучении (от простого к сложному), в развитии необходимых физических качеств, а так же в предупреждении и устранении ошибок возникающих в процессе обучения сложных вращательных элементов.

\section{СПИСОК ЛИТЕРАТУРЫ}

1. Теория и методика спортивной гимнастики : учебник в 2 т. - Т. 2/ Ю. К. Гавердовский, В. М. Смолевский. - М. : Советский спорт, 2014. - 231 с. : ил.

2. Гавердовский Ю.К. Техника гимнастических упражнений : Попул. учеб. пособие / Гавердовский Юрий Константинович. - М.: Терра-спорт, 2002. - 508 с.

3. Теория и методика физической культуры (общие основы теории и методики физического воспитания; теоретикометодические аспекты спорта и профессиональноприкладных форм физической культуры): Учеб. для интов физ. культуры. — М.: Физкультура и спорт, 1991. — 543 с, ил.

4. Смолевский, В.М. Спортивная гимнастика / Смолевский Владимир Михайлович, Гавердовский Юрий Константинович. - Киев: Олимп. лит., 1999. - 461 с.: ил. 